\title{
Determining Factors to Students' Science Achievement in the Implementation of K to 12 Spiral Progression Approach: A Mixed Method
}

\author{
Ian Reggy B. Paring ${ }^{1}$, Ann Cherry C. Cerenoㄹ, Ronald S. Decano ${ }^{3}$
}

\begin{tabular}{l} 
ARTICLE INFO \\
\hline Article History: \\
Received 12.12 .2019 \\
Received in revised form \\
23.10 .2020 \\
Accepted \\
Available online 01.01 .2021
\end{tabular}

INTRODUCTION

The educational system in the Philippines has gone it is way far from what it was before. The informal, unstructured, and devoid of methods of teaching to a more established and structured curriculum that we have today. The implementation of the K-12 Basic Education Program last 2012 aimed to decongest and enhance the basic education curriculum for learners to acquire mastery in the different learning competencies, through lengthening the educational cycle from Kindergarten up to Grade 12 of basic education (Seameo Innotech, 2012). One of the salient features of the K-12 curriculum is the 'Spiral Progression Approach this is to avoid disjunctions between stages of schooling and allows learners to learn lessons and skills appropriate to their developmental cognitive stages. The spiral progression approach is also proven to improve retention and mastery of the lesson and skills as they are reviewed and summed-up with increasing complexity and depth of learning in the succeeding year levels (Quijano, Yolanda, and Technical Working Group on Curriculum, 2012).

In the study of Bruner (1966) the spiral progression approach means to keep moving upward, but also keep returning to the fundamentals - almost as though you are constantly reviewing but adding more to the content of the lesson. Thus, by its very nature, learning involves progression. Moreover, Assessment (2008) emphasized that in the actualization of this approach, teachers must understand the progression along which students are expected to progress or develop. These progressions are both linked with appropriate instruction and assessment of learning. Extant local studies reaffirm in the benefits of the spiral progression approach in learning concepts and lessons. In the University of the Philippines, Tan (2012) explained spiral progression as inspired by Bruner's model of the spiral curriculum that students are continually returning to basic ideas as a new pile of learning is added throughout a curriculum. It is implemented to ensure that understanding of students are solidified, rather than simply memorizing the content to pass a test. Spiral progression revolves around the understanding that human cognition evolved in a step-by-step process of learning, which relied on environmental interaction and experience to form intuition and knowledge. In layman's terms, one learns best if there is a repeated experience of a concept. It is aligned with Bruner's theory of discovery learning, which posits that students learn best through constructing their learning through direct experience.
Keywords:

\begin{abstract}
This study explored the factors as determinants to students' achievement in Science with spiral progression approach aimed to know the underlying factors associated with students' level of relationship among the factors that predict students' performance, and identify which factor best predicts students' performance. A sequential exploratory mixed-method research design was
employed in the study. As a result of the analysis, this study suggested three factors that determine students' level achievement in Science: academic causal factor, student causal factor, and learning obtained a model that was significantly accountable for the variability in the responses of the factors. Moreover, a very satisfactory was observed on students' level of achievement with significantly spiral progression approach is underscored by the need for policy-guidelines revision and review,
\end{abstract} (C) IJERE. All rights reserved

Academic causal factor, student causal factor, learning milieu, students' achievement, spiral progression approach, sequential exploratory mixed-method research design. 
Despite the advantages of spiral progression, there also cited literature that found problems in the is of this approach (Snider, 2004). According to Snider, the problem with the spiral design is that the introduction rate of new concepts or ideas is either too fast or slow. Whether the lesson is easy or difficult to master, the amount of time allotted is just the same. Regardless of the complexity of the concept, they have approximately the same length of time, and most often each topic is a 1-day lesson. The issue would be that the entire time is allotted to a single concept makes it hard to deliver the instruction ensuring students' acquisition of pre-skills is happening before introducing difficult content or skill.

In a spiral curriculum, many topics are covered but in just a short period. According to Resurreccion, J.A. \& Adanza, J. (2015), on average, teachers spend their instructional time for less than 30 min across an entire year, or approximately $70 \%$ of the topics were covered and it resulted in students' failure to master important learning competencies. According to them that another disadvantage of the spiral design is that it does not promote sufficient review once units are completed. There may be some review of the previous topics within a unit, however, once the lesson jumped to the next unit, previous lessons may not be tackled again not until the next curricular year. Moreover, another important issue in the implementation of the K12 curriculum with the spiral progression approach in the Philippines as cited by De Dios (2013), those Science subjects diverge into separate disciplines in secondary education. It required teachers with knowledge in all these areas at a sufficient level. Hence, teachers which are products of major specialization in the Higher Education Curriculum cannot be expected to teach the four subject areas in science.

\section{Situation of the Problem}

Last 2012, the Philippine government launched the K-12 curriculum with the very aim to improve the country's educational system as a whole and to produce globally competitive graduates. One of the features of this curriculum is the spiral progression approach where lessons in a subject like Science are arranged from simple to complex as the curricular year progresses (de Ramos-Samala, 2018). There were studies conducted related to the implementation of the K-12 curriculum, however, there is no existing study that explores the underlying factors associated with the implementation of the spiral progression approach in this curriculum.

Extant literature also cited several issues in the conduct of the spiral progression approach in Science. Hence, with these disadvantages, this is the reason why the researcher would like to embark on knowing the underlying factors in the conduct of the spiral progression approach to better understand the implementation of the K-12 curriculum and to improve the delivery of the actual learning-teaching process. Further, this will also provide an avenue to evaluate and where the leading agency can develop and enhance pedagogical approaches suitable to the current needs of the students and teachers.

\section{Aim of the Study}

This study aimed to explore the factors as determinants to the achievement of students in Science with a spiral progression approach. This also explored the experiences and challenges encountered by the Science teachers using the spiral progression approach. Specifically, it aimed to answer the following questions: (1) What are the factors associated to learning science with spiral progression approach?; (2) What is the students' level of achievement in Science with spiral progression approach?; (3) Is there any significant relationship between the factors and students' achievement in Science with spiral progression approach?; and (4) Which factor best predicts students' achievement in Science with spiral progression approach?

\section{METHOD}

The study utilized a sequential exploratory mixed-method research design. This exploratory research used a qualitative design which is the most appropriate approach in describing the lived experiences and challenges of science teachers in the utilization of the spiral progression in basic education. According to Creswell (2014), an exploratory sequential mixed method is a design in which the researcher first begins by exploring with qualitative data and analysis and then uses the findings in a second quantitative phase.

Four Public Secondary Schools in Panabo City Division, Davao del Norte Philippines were involved in this study. The schools offer a complete Junior High School Curriculum which makes these institutions suitable for this study and likewise considered as the four big schools in Panabo City Division as per students' population. Currently, the selected secondary schools have members of the faculty in which $40 \%$ of 
the teachers are considered seasoned teachers since they are in the service for more than 10 years. The schools are recognized as top-performing secondary schools in the Region XI in both curricular and extracurricular programs.

In the qualitative phase, purposive sampling was used in choosing participants. The focus group discussion consisted of two science teachers per public secondary school. The researcher identified teachers with only those who have at least 5 years of teaching experience and have undergone K-12 training/s in teaching Science subjects to assure the reliability and validity of their lived experiences in teaching the subject under the implementation of the new curriculum. While the respondents in the quantitative phase of this study were the students in Grade 10. The researcher used the stratified random sampling in which four big public schools were chosen as part of the population. This is to ensure that each group was well represented. A total of 1,845 accounted for and using Slovin's formula, 329 respondents were included as research participants from the public secondary schools. The participants were from four different public high schools of Panabo City. The participants' age ranged from 15 to 17 years old.

\section{Material}

The main instrument that was utilized in the data collection in the qualitative aspect was a researchermade interview guide containing initial questions on the Spiral Progression Approach. The focus group discussion (FGD) guide questions, as well as the matrix, were subjected to validation and enhancement to suit the rationale of the study. Contrarywise, the instrument for the quantitative data collection was a research-made questionnaire patterned/ based on the formulated themes that emerged in the FGD. After the thematic analysis of the informants' responses, an initial research-made questionnaire was crafted, validated, modified, critiqued, enhanced, and subjected to pilot testing using exploratory factorial analysis (EFA) to craft the final research questionnaire. The initial research-made questionnaire was made up of 85 questions that saturate the different themes of the study. The result showed in the rotated factor matrix that there was a pattern observed amongst the items and which yielded a correlation (r) coefficient between $> \pm 0.30$ and $< \pm 0.90$ and likewise were grouped into three factors as exhibited in the scree plot. Thus, the final researchmade questionnaire was trimmed down to 47 questions.

Additionally, Bartlett's Test of Sphericity reconfirmed that the items in the initial survey questionnaire have a patterned relationship with a p-value of 0.000 , significantly lower than the p-value of 0.05 . In terms of Kaiser-Meyer Olkin Measure (KMO) of Sampling Adequacy, the test revealed a 0.520 KMO value greater than 0.5 which means that the entire questionnaire is suitable for EFA and the sample size is adequate for the analysis. It also showed that the over-all questionnaire with three factors has a higher reliability alpha value of 0.803 using Cronbach's Alpha. Further, as mentioned above, the three factors were determined by checking the eigenvalues and scree test. The said questionnaire used a 5-point Likert-type scale, namely; (5) Strongly agree, (4) Agree, (3) Moderately agree, (2) Disagree, and (1) Strongly disagree.

Lastly, this study utilized the Permanent Records of the respondents looking for their first-quarter grades in Science 10, profiles, and learning variables.

\section{Data Analyses}

The exploratory sequential research design is the most useful when the researcher wanted to generalize, assess, or test qualitative exploratory results obtained out from a sample or a population. The qualitative data analysis was done after the collection of all data from the field through FGD. All collected data were summed up and responses were painstakingly coded creating a long list of responses under each interview question. The list was shortlisted by putting up identical responses together and by shaping these into themes. Moreover, the identified themes were served as the major indicators for the survey questionnaire in the quantitative phase. The instrument was subjected to exploratory factorial analysis to reduce many factors into fewer numbers of factors. This technique extracts maximum common variance from all variables and puts them into a common score. Further, the determination of students' academic achievement in Science was in line with the DepEd Order No. 8 s. 2015 entitled, Policy Guidelines on Classroom Assessment for the $\mathrm{K}$ to 12 Basic Education Program was adapted to interpret the grades obtained by the Grade 10 students in the $1^{\text {st }}$ Quarter of the school year as indicated in Table 1. 
Table 1: DepEd Order No. 8 s. 2015 Grading Scale, Descriptive Equivalent, and Remarks

\begin{tabular}{ccc}
\hline Descriptors & Grading Scale & Remarks \\
\hline Outstanding & $90-100$ & Passed \\
Very Satisfactory & $85-89$ & Passed \\
Satisfactory & $80-84$ & Passed \\
Fairly Satisfactory & $75-79$ & Passed \\
Did Not Meet Expectation & Below 75 & Failed \\
\hline
\end{tabular}

In the quantitative data analysis, raw data of the students' responses on the survey questionnaires were encoded as an excel data format and were transferred to IBM SPSS Statistics 21 software for data analysis. The objective of the study is to measure the impact of the spiral progression approach in learning science was determined by knowing factors that affect the academic achievement of the students in science. Thus, a test for correlation and multiple regression analysis was utilized in this study. In simple linear regression analysis, the independent variables are the predictors which were the identified themes/factors after the EFA was carried out and the dependent variables were the grades/ achievements of the students in the first Grading period which were measured/group using the Grading scale based on DepEd Order No. 8, s. 2015. A correlation test was done for the significant relationship between the identified factors and students' level of achievement in Science.

\section{FINDINGS}

\section{Emerging Themes Associated to Learning Science with Spiral Progression Approach}

As the informants were interviewed through FGD about the factors associated with students' achievement in teaching science with spiral progression approach, four major themes/factors surfaced with corresponding clustered themes enclosed in parenthesis, namely, Students' Curricular Foundation (Intellectual Readiness, Acquisition of the previous Learning Competencies, and Behavioral scene), Learning Milieu (Insufficient laboratory apparatus and equipment, Insufficient number of classroom and other facilities, and Lack of Instructional Materials), Teaching Pedagogy (Lack of pedagogical training, and Meaningful Learning Experiences), and Time element (Time Allotment, Class disturbances, and Curricular deficiency and congestion).

\section{Factors Associated to the Achievement in Science with Spiral Progression Approach}

The quantitative phase sought to confirm the identified factors out from the emerging themes which were taken from the FGD and identify which of these themes/factors predict the students' achievement in the implementation of the spiral progression approach of the K to 12 Program. These themes/factors were analyzed using exploratory factorial analysis (EFA) to exact the final factors as shown in Table 2.

Table 2. Identified factors for Spiral Progression Approach

\begin{tabular}{cl}
\hline \multicolumn{1}{c}{ Factors } & \multicolumn{1}{c}{ Sub-factors } \\
\hline A. Academic causal factor & A1. Pedagogical Training \\
& A2. Meaningful Learning Experiences \\
& A3. Time Allotment \\
& A4. Curricular deficiency and congestion \\
B. Student causal factor & B1. Behavioral Scene \\
& B2. Intellectual Readiness \\
C. Learning Milieu & C1. Lack of Instructional Materials \\
& C2. Insufficient Classroom and other Facilities \\
& C3. Class Disturbances \\
\hline
\end{tabular}

Table 3 showed that the respondents agree that the statements under academic causal factors were often true. On the other hand, respondents moderately agree that the statements under learning milieu and student causal factors are sometimes true. Lastly, the result presented that the respondents have an overall level of agreement as moderately agree that most of the statements under the three factors identified were sometimes true in the perceptions and experiences of the students towards their performance in Science 10. 
Table 3: Summary of the Students' Level of Agreement to Factors related to Science Performance

\begin{tabular}{lccc}
\hline \multicolumn{1}{c}{ Factors } & Mean & Sd & Qualitative Description \\
\hline Academic Causal Factor & 3.65 & 0.9 & Agree \\
Learning Milieu & 3.13 & 1.03 & Moderately Agree \\
Student Causal Factor & 3.31 & 0.96 & Moderately Agree \\
Overall & $\mathbf{3 . 3 6}$ & $\mathbf{0 . 6 1}$ & Moderately Agree \\
\hline
\end{tabular}

\section{Level of students' achievement in Science with Spiral Progression Approach}

Figure 1 showed the frequency distribution of students' level of achievement in Science with the spiral progression approach. The data revealed that out of 329 students, there were 104 or $32 \%$ which were identified at the Outstanding level. On the contrary, there were 48 student-respondents, or $15 \%$ were classified as Fairly satisfactory and 16 student-respondents or 5\% were categorized as Did not meet expectation.

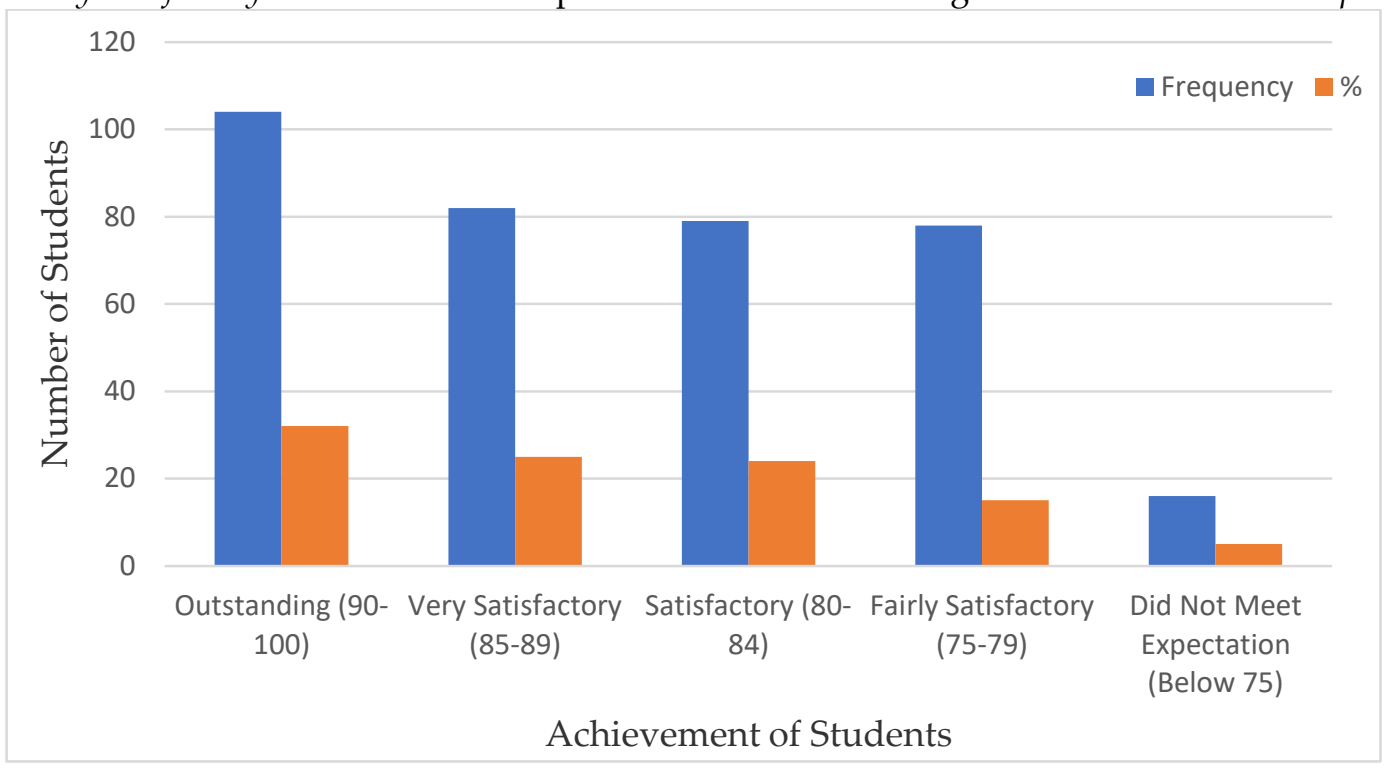

Figure 1: Frequency Distribution of Students' Level of Achievement in Science

Table 4 is the summary of students' level of achievement in Science which shows an 84.88 or very satisfactory average mean of students' achievement in Grade 10 Science.

Table 4. Summary of Students' Level of Achievement in Science

\begin{tabular}{cccc}
\hline Variable & Mean & Sd & Qualitative Description \\
Grade & 84.88 & 5.92 & Very Satisfactory \\
\hline
\end{tabular}

Test of Correlation among the Factors and Students' Achievement in Science with Spiral Progression Approach

Correlation results in Table 5 revealed that the overall computed r-value of identified factors namely; academic causal factor (ACF), students causal factor (SCF), learning milieu (LM) for students' achievement against the grade of Science was -.23 r-value or slight relationship with a p-value of .000 which was lesser the .05 level (two-tailed) of significance. 
Table 5. Relation of students' level of achievement in Science and identified factors.

\begin{tabular}{llcl}
\hline \multicolumn{1}{c}{ Factors } & \multicolumn{2}{c}{ Academic Performance } & Decision over $\mathbf{H}_{\mathbf{o}}$ \\
& r-value & p-value & \\
\hline Teacher causal factor & $-.174^{* *}$ & .002 & Rejected \\
Learner causal factor & $-.150^{* *}$ & .007 & Rejected \\
Learning Milieu & $-.225^{* *}$ & .000 & Rejected \\
\hline Overall & $-.229^{* *}$ & .000 & Rejected \\
\hline
\end{tabular}

\section{Predictors to Students' Achievement in Science with Spiral Progression Approach}

Table 6 revealed that the value of $\mathrm{R}(=.52)$ showed a low or slight correlation between the factors (ACF, SCF, LM) and students' level of achievement in science. Consequently, the value of R-square $\left(\mathrm{r}^{2}=.27 \mathrm{X}\right.$ $100=27 \%$ ) which indicated that the model has low fit to this data. However, the regression model showed that the computed F-value was 5.33 with a $p$-value of 0.001 . Hence, the overall model can be statistically expressed as $Y^{\prime}($ Students' achievement $)=67.41+2.24$ (academic causal factor $)+2.90$ (student causal factor $)+.06$ (learning milieu).

Table 6. Influence of the factors of the spiral progression approach to students' Grade in Science.

\begin{tabular}{|c|c|c|c|c|}
\hline \multicolumn{5}{|c|}{ Unstandardized Coefficient } \\
\hline Variables & B & Std. Error & t-value & p-value \\
\hline Constant & 67.412 & 4.577 & 14.728 & .000 \\
\hline ACF & 2.239 & .859 & 2.607 & 010 \\
\hline SCF & 2.898 & 1.029 & 2.817 & .005 \\
\hline LM & .059 & .595 & .099 & .921 \\
\hline $\mathrm{R}=.516$ & & & $F_{\text {value }}=5.325$ & \\
\hline $\mathrm{R}^{2}=.267$ & & & $\mathrm{~F}_{\text {significance }}=0.001$ & \\
\hline No. of observations $=329$ & & & & \\
\hline
\end{tabular}

\section{RESULT, DISCUSSION, AND SUGGESTIONS}

The study explores the themes/factors influencing the achievement of students in Science with the spiral progression approach through teachers' experiences and challenges encountered. Findings indicated that there were four major themes/factors surfaced with corresponding clustered themes based on the thematic analysis, these were students' curricular foundation (intellectual readiness, acquisition of the previous learning competencies, and behavioral scene), learning milieu (insufficient laboratory apparatus and equipment, insufficient number of classroom and other facilities, and lack of instructional materials), teaching pedagogy (lack of pedagogical training, and meaningful learning experiences), and time element (time allotment, class disturbances, and curricular deficiency and congestion). Informants cited several problems concerning the implementation of the spiral progression approach. Informants said that "whenever we re-teach the previous concept, it can cause delay on the current learning competencies for the quarter. Thus, there will be a dilemma in deciding whether you will teach it faster to cope with the delays or follow students' pacing yet you can't finish the entire lessons.". They also explained the problem of students in acquiring the previous learning competencies, "I have also encountered the same problem. When I asked my student if they have remembered something in the previous science classes, most of them said, "They can't recall anymore".

Further, other informants shared issues on the learning environment which include insufficient instructional materials, laboratory equipment, and apparatus, and other school facilities. One informant expounded that "Yes! Science facilities and equipment are the concerns in my class. As a remedy, I searched for other alternatives just to give hands-on experiment but of course, it's different.", and some told that "...materials are also considered an issue, especially in my Physics class. It is difficult to acquire even if I will request those, but I know it will be provided very late". On the other side, informants also mentioned the problems in teaching pedagogy, teacher's time allotments, and activities that hamper the teaching-learning schedules. Informants cited that "Only a few were sent to join the said training". They added that "There are activities in the learning materials that are not feasible to be implemented in just one hour. Preparing for the materials needed can exhaust all your time", and 
"In my case, sometimes I can't attend my class since I am the Brigada coordinator and especially that August is our evaluation".

Based on the exploratory factor analysis on the gathered themes in the qualitative phase of this study, it revealed that three major factors emerged namely, (1) academic causal factor (ACF) which was attributed to teachers' qualities or characteristics used in this study, (2) student causal factor (SCF) which was used to represent students' interests and readiness towards the subject, and (3) learning milieu (LM) which was utilized to exhibit school supports in enriching school environment to learning. The study conducted by Alshammari et al. (2017) cited similar factors in the academic achievement of student nurses such as studentrelated factor, school-related factor, home-related factor, and teacher-related factor. It also matches the study of Diaz (2003) reported that most studies have mentioned three distinct factors of poor achievement, these are teachers (academic causal factors), students (personal causal factors), and parents (family causal factors). Moreover, Aru (2014) which identifies poor pedagogy in science education, negative attitude towards science subjects among students, and lack of resources in the school have contributed to the poor achievement in science subjects in a secondary school in Tanzania.

Table 3, showed that the respondents' level of agreement to factors associated with students' achievement in Science. The result suggested that students agreed that the different statements as indicated in the survey questionnaire were sometimes true and can be attributed as factors to students' achievement in Grade 10 Science within the implementation of the spiral progression approach. Moreover, these agreements of students to the different statements exemplified that their perceptions and experiences towards learning Science 10 have an important influence on students' performance in the subject.

Furthermore, Figure 1 revealed that out of 329 students, there were 104 or 32\% which were identified at the Outstanding level. On the contrary, there were 48 student-respondents, or 15\% were classified as Fairly satisfactory and 16 student-respondents or 5\% were categorized as Did not meet the expectation. The results above coincide with the National Achievement Test Result of Region XI, the school year 2017-2018 conducted by the Bureau of Education Assessment revealed that $64.70 \%$ of student takers were considered as low proficient or fairly satisfactory and $19.59 \%$ were classified as not proficient or did not meet the expectation. Hence, this implied that there were students at the secondary level that need attention and help to increase their level of achievement in Science. The overall mean of 84.88 or very satisfactory average mean of students' achievement in Grade 10 Science implied that they have acquired or developed the fundamental knowledge and skills, and core understanding required by the subject area. However, the standard deviation of 5.93 exemplified that students grasped the concepts and contents of Science subject into a wide range of levels. This has been proven by different studies on learning styles. Vainionpaa (2006) claimed that students learn differently, and it is evident that learners differ in the way they learn. This dissimilarity is because learners prefer different learning styles, have different learning motivation, and differ from each other in self-confidence. Thus, the level of achievement of students varied significantly as illustrated in Table 4.

Consequently, the correlated data among the factors and students' achievement in science with the spiral progression approach indicated a slight relationship with a p-value of .002 which was lesser than the .05 level (two-tailed) which means that the identified factors were significant. The data were corroborated with the study of Ochieng (2012) that there was a weak negative relationship between academic causal factors and academic achievement in Mathematics. But most of the researches revealed a significant relationship between ACF and students' level of achievement like in the study of conducted by Aldossary, A. et.al. (2008) which concluded that from among several factors posing a great impact on the academic achievement of students, teacher-related factors top the list. Dangol, R. and Shrestha, M. (2019) that learning readiness exhibited a positive correlation towards educational achievement among school students. On the other hand, it is up to the students to wholeheartedly dedicate themselves to learning and improve their academic achievement (Kapur, 2018). Likewise, Schools without basic facilities and resources such as prescribed textbooks often have a low academic achievement (Ali, H. et.al., 2019). Similarly, a study conducted by Rockoff (2009) showed that class disturbances are an attribute to LM. He further stressed that teaching disruption either personal-called or official activities can cause a detrimental effect on students' achievement.

Lastly, the derived model which is $Y^{\prime}$ (Students' achievement) $=67.41+2.24($ ACF $)+2.90(S C F)+.06(L M)$, indicated that in every one-unit change in the factors brings a $26.7 \%$-unit change in the level of students' level of achievement. The variance (27\%) of the grades of the students in Science was attributed to ACF, SCF, 
and LM. This result is congruent to the study conducted by Tosun et al., (2015) which identified the studentsourced, and teacher-sourced factors affect the academic achievement based on the perceptions of students in levels of middle school, high school, and university. Likewise, in the Philippine setting, Merza et al., (2018) cited the curriculum factor, teacher factor, student factor, and school factor affecting students' achievement in the implementation of the Spiral Progression Approach. However, the difference of $73 \%$ was influenced by other factors that were not covered by this study. Diaz (2003) reported that though many of the recent studies showed three elements that intervene the students' achievement, that is, parents, teachers, and students, but still the factors and its influence on academic achievement may vary from one academic environment and indeed from one cultural setting to another.

\section{Research Limitations and Advanced Research Suggestions}

This study explored academic causal, student causal, and learning milieu as determining factors of students' achievement in science with the spiral progression approach. These factors were identified and explored based on the encountered experiences of teachers. However, the exploratory nature of this study has its limitation where it was only conducted and implemented in 4 public schools in Panabo City. Therefore, for future research, it is recommended that the results be replicated on a large number of schools which covers schools in far-flung areas where they also encountered different problems and issues in the curriculum. Further, using the significant findings, similar studies should be conducted focusing on some underlying factors which were not included in this research to know the areas which are not well covered.

Moreover, based on the results obtained, it is also recommended that, firstly, the Department of Education (DepEd) must intensify training and seminars to teachers relative to the content of $\mathrm{K}$ to 12 Curriculum per learning area. Teachers should be trained on how to deliver the subject content, teaching style, approach, and the learning materials to be used. This will allow the teachers to be able to meet the learning competencies of the new curriculum. Further, DepEd should seek an effective mechanism on how to assess or evaluate the implementation of these training in the field. The findings also suggest prioritizing teachers who were hired recently for them to cope up with the teaching pedagogies in this new curriculum. Secondly, the achievement level in science exhibited by the respondents demands innovative ideas to motivate students to learn the science subject. At the school level, School Heads/Principals must utilize DepEd initiated programs like school learning action cell (SLAC) sessions where teachers, master teachers, and department coordinators share issues relevant to students' performance on a certain learning area and can discuss ways and means to scaffold students towards the attainment of learning competencies. In the said session, teachers could also share best practices such as the utilization of modern methods in teaching including the use of technology like computers in teaching science to sustain students' interest in the most science topic. Lastly, the government, parents, school administration, and the community at large should work hand in hand to ensure that the teaching and learning milieu is conducive to the teachers and students for effective learning to happen. The school must maximize the utilization of school maintenance and other operating expenses (MOOE) and allocate an appropriate amount to instructional materials, facilities, and equipment as required in the implementation of the spiral progression approach. Additionally, the ParentTeacher Association can also initiate projects which support the school in improving the learning environment suitable to learning like donating technology-based equipment and the likes which promote modern ways in delivering instruction.

\section{REFERENCES}

Aldossary, A., While, A. and Barriball, L. (2008), Health care and nursing in Saudi Arabia. International Nursing Review, 55: 125-128. doi:10.1111/j.1466-7657.2007.00596.x

Ali, S., Haider, Z., Munir, F., Khan, H., \& Ahmed, A. (2013). Factors contributing to the students academic performance: A case study of Islamia University sub- campus. American Journal of Educational Research, $1,283-289$.

Bruner, J. (1966). Toward a theory of instruction. Cambridge, MA: Harvard University Press.

Costello, AB \& Osborne, Jason. (2005). Best practices in exploratory factor analysis: Four recommendations for getting the most from your analysis. practical assessment.Research \& Evaluation, 10. 1-9.

Creswell, J. W. (2014). Qualitative inquiry and research design: Choosing among five approaches (3rd ed.). Thousand Oaks, CA: Sage. 
Dangol, Rita \& Shrestha, Milan. (2019). Learning Readiness and Educational Achievement among School Students. The International Journal of Indian Psychology. 7. 467-476. 10.25215/0702.056.

De Dios, A. (2013). Spiral curriculum: When and How? Redundant vs Progressive? https://www.philippinesbasiceducation.us/2013/05/spiral-curriculum-when-and-how.html

De Ramos-Samala, H. (2018). Spiral progression approach in teaching sciecne: A case study. KnE Social Sciences, 3(6), 555-567. https://doi.org/10.18502/kss.v3i6.2404

Díaz, A.. (2003). Personal, family, and academic factors affecting low achievement in secondary school. Electronic Journal of Research in Educational Psychology and Psycho Pedagogy,1.

Kapur, R. (2018). Factors influencing the students academic performance in secondary schools in India. University of Delhi

Merza L.L, Orge N.B, Agatep J.L \& Edaño D. (2018). Factors affecting the implementation of spiral progression approach in relation to students' academic performance in mathematics. International Journal of Social Science and Humanities Research, 6, 4, 490-495.

Ochieng', W. (2015). Self-efficacy and academic achievement among secondary schools in kenya: mathematics perspective. Unpublished Thesis, University of Nairobi.

Putnam, J. (1997). Cooperative learning in diverse classroom. Upper Saddle River, New Jersey: Printice-Hall, Inc.

Quijano, Y. S. \& Technical Working Group on Curriculum (2012). Orientation for K to 12 division coordinators. DepED Complex.

Resurreccion, J.A., \& Adanza, J.R. (2015). Spiral progression approach in teaching science in selected private and public schools in Cavite. International Conference on Research in Social Sciences, Humanities and Education (SSHE-2016) May 20-21, Cebu (Philippines).

Rockoff, J.E. (2009). The impact of teaching disruptions on student achievement. Columbia Business school and NBER.

https://www0.gsb.columbia.edu/faculty/jrockoff/herrmann_rockoff_teaching_disruptions_6_5_09.pdf

Snider, V.E. (2004). A comparison of spiral versus strand curriculum. Journal of Direct Instruction, 4(1).

Tan, M. (2012). Science education in the Philippines: Where To? National Institute for Science and Mathematics Education Development, University of the Philippine.

Tosun, C, Ilhan, N, Tatar, E, Hairless, C. \& Karakuyu, Y . (2015). Science success of secondary, high school and university students. Mehmet Akif Ersoy University Faculty of Education Journal, 1 (35), 29-45 . Retrieved from https://dergipark.org.tr/tr/pub/maeuefd/issue/19408/206314

Vainionpää, J.E. (2006). Different learners and learning materials in e-learning. Tampere University. 